\title{
Marek's disease virus challenge induced immune-related gene expression and chicken repeat 1 (CR1) methylation alterations in chickens
}

\author{
Fei Tian ${ }^{1}$, Juan Luo ${ }^{1}$, Huanmin Zhang ${ }^{2}$, Shuang Chang ${ }^{3}$, Jiuzhou Song ${ }^{1 *}$ \\ ${ }^{1}$ Department of Animal \& Avian Sciences, University of Maryland, College Park, USA \\ ${ }^{2}$ USDA, ARS, Avian Disease and Oncology Laboratory, East Lansing, USA \\ ${ }^{3}$ Department of Animal Sciences, Michigan State University, East Lansing, USA \\ Email: songj88@umd.edu
}

Received 28 March 2012; revised 25 April 2012; accepted 20 May 2012

\begin{abstract}
Marek's disease virus (MDV) challenge induces lymphoma in susceptible chickens. Host genes, especially immune related genes, are activated by the virus. DNA methylation is an epigenetic mechanism that governs gene transcription. In the present study, we found that expression of signal transducer and activator of transcription 1 (STAT1) was upregulated at 10 days post infection (dpi) in MD susceptible chickens, whereas interleukin 12A (IL12A) was elevated in both resistant and susceptible chickens. However, we did not observe MDV-induced DNA methylation variations at the promoter CpG islands (CGIs) in STAT1 and IL12A. Interestingly, the methylation levels at Chicken Repeat 1 (CR1), the transposable elements (TEs) located upstream of two genes, were different between resistant and susceptible chickens. Furthermore, a mutation was identified in the CR1 element near IL12A. The impact of the point mutation in transcriptional factor binding is to be examined in the near future.
\end{abstract}

Keywords: Marek's Disease; Chicken Repeat 1; DNA Methylation; Gene Expression

\section{INTRODUCTION}

Marek's disease (MD) is a lymphoma in chicken caused by the infection of Marek's disease virus (MDV). The infectious disease in chickens includes three phases, from the early cytolytic stage at 5 days post infection (dpi), to latent stage around 7 - $10 \mathrm{dpi}$, and then the late cytolytic phase and transformation [1]. Recently, several studies revealed that expression profiles of immune related genes were altered post MDV infection in chickens [2-4], suggesting those genes play important roles in in-

*Corresponding author. nate and adaptive immunity in responses to MDV infection.

As we have known, viral infection is one of the environmental factors triggering DNA methylation alterations and consequently changing gene expression profiles. DNA methylation frequently occurs at the $\mathrm{CpG}$ sites, and increased methylation level at the promoter regions is associated with transcriptional silencing [5]. Notably, the association between DNA methylation and gene expression was observed in Marek's disease resistant and susceptible chickens post MDV infection [6,7].

Chicken Repeat 1 (CR1), a class of non-LTR retrotransposons comprising 11 subfamilies (B-H, X, Y, C3 and $\mathrm{C} 4$ ), constitutes $80 \%$ of all the interspersed repeats in the chicken genome [8,9].

Most of CR1 elements are truncated at their 5'UTR and conserved at 3'UTR [10-12]. The distribution of CR1 elements in high GC content regions makes them the potential targets for DNA methyaltion [9]. The loss of DNA methylation on repetitive DNA was associated with cancer $[13,14]$. However, little is known about the effects of MDV infection on methylation status of chicken repeat 1 , the predominant transposable element in chicken genome.

This study aimed to uncover the MDV challenge induced DNA methylation variations on CR1s in MD resistant and susceptible chickens, and its subsequent effects on gene expression. Chicken line $6_{3}$ and line $7_{2}$, two highly inbred lines of specific pathogen free (SPF) chickens, are both susceptible to MDV, but line $6_{3}$ is resistant to MD tumors while line $7_{2}$ is highly susceptible to MD tumors [15]. Our previous result demonstrated that MDV replication was repressed infected line $6_{3}$ than line $7_{2}$ [16]. Cytokines and other immune related genes were differentially expressed in chickens after MDV infection [17-19]. In this study, we found that two important immune genes, signal transducer and activator 
of transcription 1 (STAT1) and interleukin $12 A$ (IL12A) were activated in line $6_{3}$ and line $7_{2}$ after MDV infection. Instead of changing methylation level at promoter $\mathrm{CpG}$ islands, MDV infection influenced the methylation status of two CR1s near the promoters, which may be associated with STAT1 and IL12A mRNA expression levels. The finding may give us new insight of the potential roles of retrotransposons in MD resistance and susceptibility in chicken.

\section{MATERIALS AND METHODS}

\subsection{Viral Challenging Experiment and Sample Preparation}

SPF chickens from highly inbred lines $6_{3}$ and line $7_{2}$ were sampled for this study. The chickens from each of the two lines were divided into two groups. The infected groups were challenged with 500 PFU of 648A passage 40 viruses intraabdominally, at day 5 after hatch, and were designated as treatment groups. The control groups were not challenged with the MDV. Chickens from both treatment and control groups were euthanized at 10 days post infection and fresh spleen samples were collected. The spleen samples were immediately stored in RNAlater solution (QIAGEN), and then placed at $-80^{\circ} \mathrm{C}$ for DNA and RNA extractions. The challenged experiments were conducted in the BSL-2 facility at the USDA-ARS, Avian Disease and Oncology Laboratory at East Lansing, Michigan, USA, following the Guidelines for Animal Care and Use (Revised April, 2005) established by ADOL's IACUC.

\subsection{Purification and Quantification of mRNA Levels}

RNA was extracted from four samples per group using RNeasy Mini Kit (QIAGEN) based on the standard method described by the manufacturer, including the on column DNase digestion, and quantified by Nanodrop. Reverse transcription and quantification of mRNA were performed with SuperScript ${ }^{\mathrm{TM}}$ III Reverse Transcriptase (Invitrogen) with oligo (dT) ${ }_{12-18}$ primers (Invitrogen), and the QuantiTect SYBR Green PCR Kit. In the reverse transcription control, PCR water (Invitrogen) was used to replace miRNA or RNA samples. Briefly, $1 \mu \mathrm{g}$ of purified miRNA or total RNA was used for reverse transcription, respectively, and $2 \mu \mathrm{l}$ of RT products (1:5 dilutions) were used for real-time PCR quantification. Two types of controls were applied in real-time PCR, including reverse transcription control and blank using PCR water. No amplicon was observed in the controls. A final volume of $20 \mu \mathrm{l}$ real-time PCR product was incubated in an iCycler iQ PCR System (Bio-Rad), and each was performed on four biological replicates from the treat- ment per line in each experiment. Three independent experiments were carried out for each gene. $G A P D H$ (glyceraldehyde-3-phosphate dehydrogenase) were used as normalization.

Forward and reverse primers for quantification of IL12A and STAT1 are listed in Table 1.

\subsection{DNA Preparation and Bisulfite Treatment}

Genomic DNA was extracted by using Nucleo Spin kit (Macherey-Nagel) from four samples of each group, and the concentration was measured by Nanodrop. Sodium bisulfite conversion reagents were used to treat $500 \mathrm{ng}$ of DNA (EZ DNA Methylation Golden Kit) using the standard protocol provided by the manufacturer.

\subsection{Pyrosequencing and Bisulfite Sequencing}

PCR primers (Table 1) were designed to amplify multiple CpG sites in specific CGIs and CR1-F at an upstream region of $I L 12 A$ and STAT1. Pyrosequencing and bisulfite sequencing were applied to detect the methylation levels of $S T A T 1$ and $I L 12 A$, respectively. For pyrosequencing, we used biotin labeled universal primer in the PCR reaction. The bisulfite PCR included $1 \mu \mathrm{l}$ of $1: 5$ diluted bisulfite converted DNA, primers and PCR reagents from Hotstar Taq polymerase kit (QIAGEN) with four biological replicates. The methylation level detection was carried out individually by Pyro Q-CpG system (PyroMark ID, Biotage, Sweden) using $20 \mu \mathrm{l}$ of PCR products. For bisulfite sequencing, the equal amount of DNA from four MDV challenged or control samples from each chicken line were pooled together, serving as a template for the bisulfite conversion and the bisulfite PCR, and then PCR products were purified (QIAquick Gel Extraction Kit, QIAGEN). The purified PCR products were ligated to PCR ${ }^{\circledR} 2.1$ Vector (The Original TA cloning $^{\circledR}$ Kit, Invitrogen), transformed to DH5 $\alpha$ competent cells (ZYMO Research), and screen the white colonies for successful insertions after incubation at $37^{\circ} \mathrm{C}$ overnight. Ten white colonies from each group were cultured at $37^{\circ} \mathrm{C}$ shaker overnight. The plasmid DNA was isolated using QIAprep ${ }^{\circledR}$ Miniprep Kit (QIAGEN), and then M13 reverse primer was used to sequence all the samples.

\subsection{Transcription Factor Binding Sites Prediction}

Transcription factor binding sites (TFBS) were predicted based on the sequence of CR1-F elements upstream of STAT1 and IL12A using a web based tool (http://www.cbrc.jp/research/db/TFSEARCH.html). The threshold score was set as 90 to filter out poorly conserved TFBSs [20]. This algorithm predicts TFBSs based 
Table 1. Primers for bisulfite PCR and real time-PCR.

\begin{tabular}{|c|c|c|}
\hline \multicolumn{2}{|c|}{ Genes } & \multirow{2}{*}{$\frac{\text { Sequences }}{\text { CATAAAAACGG-3' }}$} \\
\hline$H_{12} \mathrm{CD} 151^{\mathrm{A}}$ & Forward & \\
\hline 1LILA-СК & Reverse & 5'-ССАСАТССССАТААТТСТАААСА-3' \\
\hline \multirow{2}{*}{$I L 12 A-\mathrm{CR} 1-\mathrm{F}-2^{\mathrm{A}}$} & Forward & 5'-GGGGTTATTATTTTTGGAGGTGT-3' \\
\hline & Reverse & 5'-ССАТАСТТТТАСССТТАСААТСАС-3' \\
\hline \multirow{3}{*}{$I L 12 A-C p G$ Island $^{\mathrm{A}}$} & Forward & 5’-GTCGATGTCGTGTTTTGTTATGT-3' \\
\hline & Reverse & 5’-GGGACACCGCTGATCGTTTAAACTCCCCGACACATCAATAC-3' \\
\hline & Sequencing & 5'-TTTTGTTCGATGAAATTG-3' \\
\hline \multirow{3}{*}{ STAT1-CR1-F ${ }^{\mathrm{A}}$} & Forward & 5'-TGTTTAGGAAGGTGGTGGAGTTA-3' \\
\hline & Reverse & 5’-GGGACACCGCTGATCGTTTACCTTCCСАCAAAACСАAАATTA-3' \\
\hline & Sequencing & 5'-GGAAGGTGGTGGAGTTA-3' \\
\hline \multirow{3}{*}{ STAT1-CpG Island ${ }^{\mathrm{A}}$} & Forward & 5’-TGTAAYGAAGTAAAATAGGYGAGA-3' \\
\hline & Reverse & 5'-GGGACACCGCTGATCGTTTATCAACCTACACTACRCAACCTAA-3' \\
\hline & Sequencing & 5'-TAAAATAGGCGAGATATAAG-3' \\
\hline \multirow{2}{*}{$I L 12 A^{\mathrm{B}}$} & Forward & 5’-GATCCGGGGCCTGGAAACTGC-3' \\
\hline & Reverse & 5’-TGAGGTTCCCCAGCTCTGCCT-3’ \\
\hline \multirow{2}{*}{$G A P D H^{\mathrm{B}}$} & Forward & 5’-GAGGGTAGTGAAGGCTGCTG-3' \\
\hline & Reverse & 5'-ACCAGGAAACAAGCTTGACG-3' \\
\hline \multirow{2}{*}{$S T A T 1^{\mathrm{B}}$} & Forward & 5'-ATCAGAAGGGCTCCAGAACA-3' \\
\hline & Reverse & 5'-GCAGGGAGATTGGAGATTCA-3' \\
\hline
\end{tabular}

${ }^{\mathrm{A}}$ : Primers for bisulfite PCR; Y stands for $\mathrm{C} / \mathrm{T} .^{\mathrm{B}}{ }^{\text {: }}$ Primers for $\mathrm{qRT}-\mathrm{PCR}$.

on the correlation calculation with binding site profile matrices, and written by Yutaka Akiyama (Kyoto University).

\section{RESULTS}

\subsection{IL12A and STAT1 mRNA Expression}

In this study, we first detected the mRNA levels of STAT1 and $I L 12 A$ at the latent stage of MDV infection. As shown in Figure 1(a), the transcription of STAT1 was significantly activated in infected line $7_{2}$, showing an approximate five-fold increases than noninfected chickens $\left(\mathrm{p}<0.01\right.$ ), whereas in line $6_{3}$, STAT1 was slightly upregulated after MDV infection but not significantly different from its control group ( $p>0.05$ ). Moreover, the STAT1 transcriptional levels did not show statistical significance between infected line $6_{3}$ and line $7_{2}$ (Figure 1(a)). However, the expression of $I L 12 A$ was dramatically elevated in MDV challenged line $6_{3}$ and line $7_{2}$ groups compared to their control groups ( $\mathrm{p}<0.01$ ). Meanwhile, in infected chickens, the $I L 12 A$ transcripts were significantly higher in line $6_{3}$ chickens than in line $7_{2}$ chickens (Figure 1(b)). The expression levels of the two genes were not significantly different between the line $6_{3}$ and line $7_{2}$ control groups (Figures 1(a) and (b)).

\subsection{DNA Methylation at CGIs Upstream of STAT1 and IL12A}

To understand how MDV infection induces differential gene expression, DNA methylation at the CpG islands (CGIs) located around transcriptional start sites (TSS) of $S T A T 1$ and $I L 12 A$ were investigated (we named them as $S T A T 1$ CGI and $I L 12 A \_C G I$, respectively) by the pyrosequencing method. The $S T A T 1$ CGI overlaps with the 5'UTR and potential promoter region, and contains 6 CpG sites which are 345 bp away from the TSS. We found that all the $\mathrm{CpG}$ sites remained hypomethylated (less than 10\%) in the control and infection groups of both lines. The methylation changes were less than $1 \%$ between the control and MDV infection groups in both lines (Figure 2(a)). The IL12A_CGI, containing $78 \mathrm{CpG}$ sites, covers the promoter region and entire the first exon. The methylation levels of $5 \mathrm{CpG}$ sites, $10 \mathrm{bp}$ upstream of TSS, were measured. The methylation status of the IL12A_CGI was not different between the challenged and control groups of both lines (Figure 2(b)). On average, the $I L 12 A \_C G I$ was significantly less methylated in line $6_{3}$ than that in line $7_{2}$ (Figure 3 ), and the methylation difference reached $10 \%$ in the first CpG site.

\subsection{DNA Methylation of CR1-F Elements Upstream of STAT1 and IL12A}

Since MDV infection induced DNA methylation altera- 
STAT1 mRNA

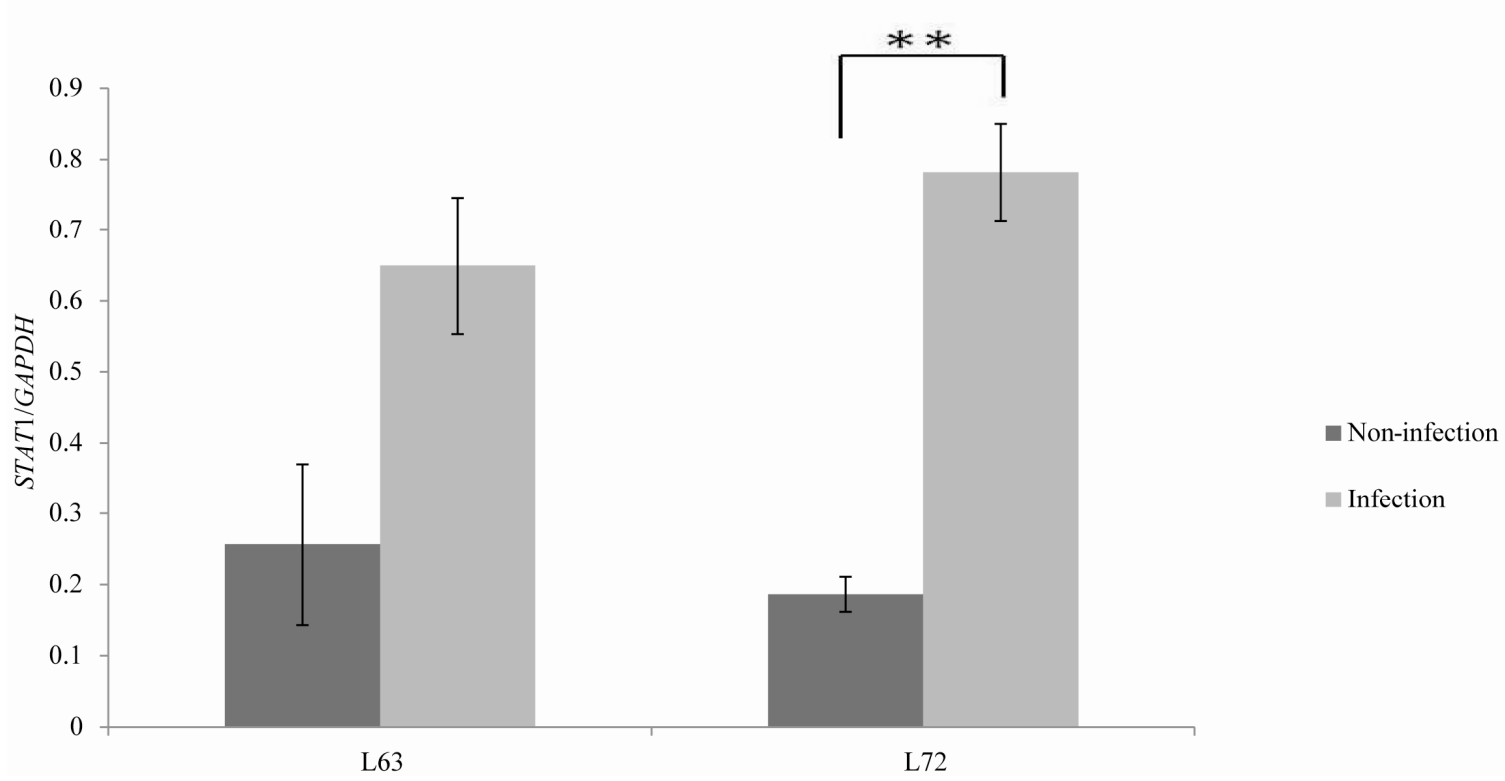

(a)

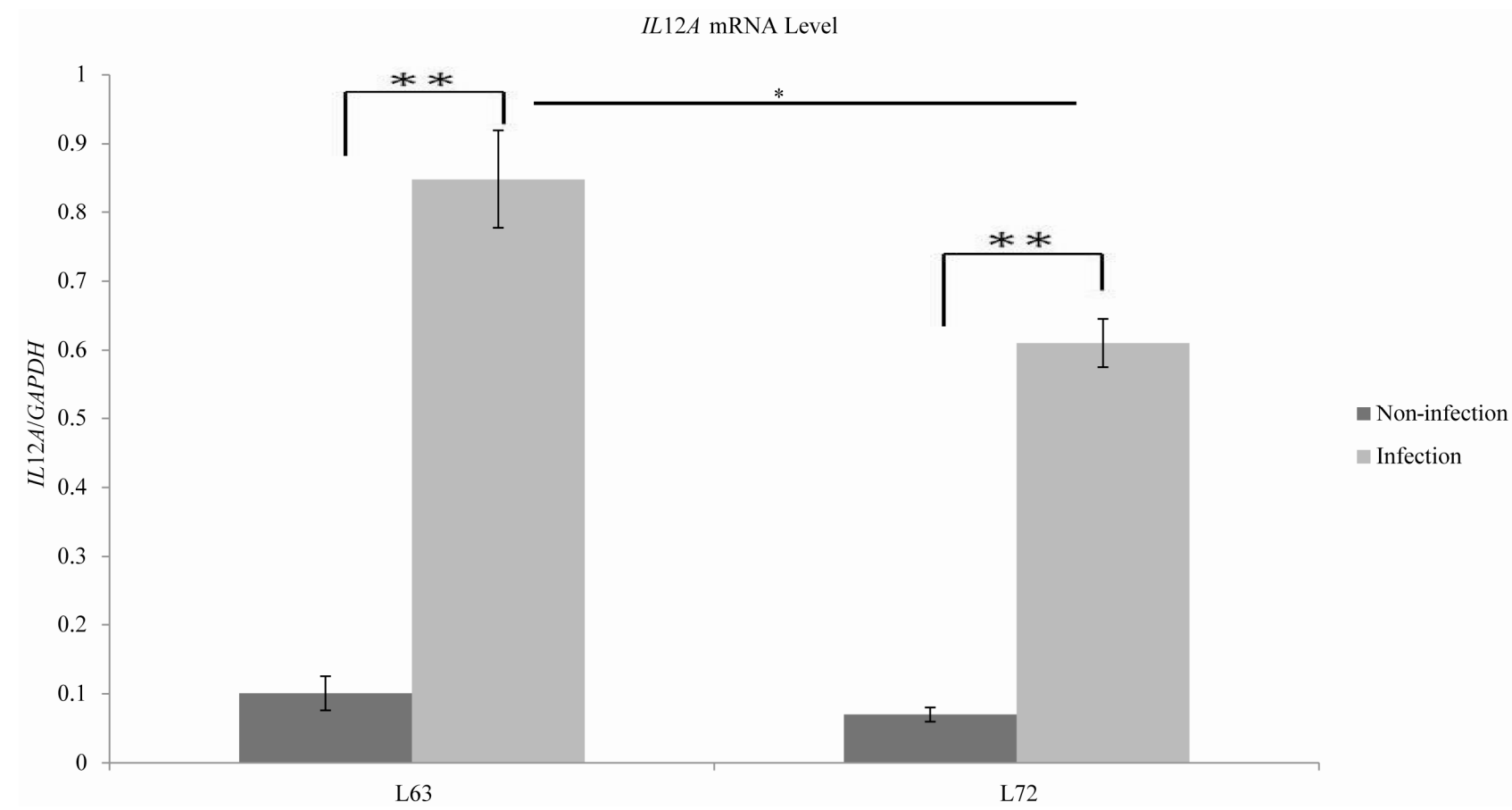

(b)

Figure 1. The relative mRNA levels of $S T A T 1$ (a) and $I L 12 A$ (b) in non-infected and infected Line $6_{3}$ and Line $7_{2}$ was quantified by qRT-PCR and normalized using $G A P D H(\mathrm{n}=4$, mean $\pm \mathrm{SD})$. The one or two asterisks indicate the mRNA level was significantly different with $\mathrm{p}<0.05$ or $\mathrm{p}<0.01$. L7 $7_{2}$ : line $7_{2} ; \mathrm{L}_{3}$ : line $6_{3}$.

tions were not observed at promoter CGIs, we traced further upstream sequences of STAT1 and IL12A. Interestingly, two CR1-F elements (referred as STAT1_CR1_F and IL12A_CR1_F, respectively) are located close to CGIs containing several CpG sites. The STAT1_CR1_F with $636 \mathrm{bp}$ in length resides around $1.2 \mathrm{~kb}$ upstream of
STAT1 TSS. Using the pyrosequencing method, we found that the methylation levels of $4 \mathrm{CpG}$ sites in this element were $24 \%$ and $25 \%$ in the control groups of line $6_{3}$ and line $7_{2}$, respectively, which decreased to $20 \%$ and $17 \%$ in the corresponding challenged groups, showing nearly a 5\% - 10\% reduction after MDV infection (Figure 4(a)). 
STAT1 CpG Island Methylation

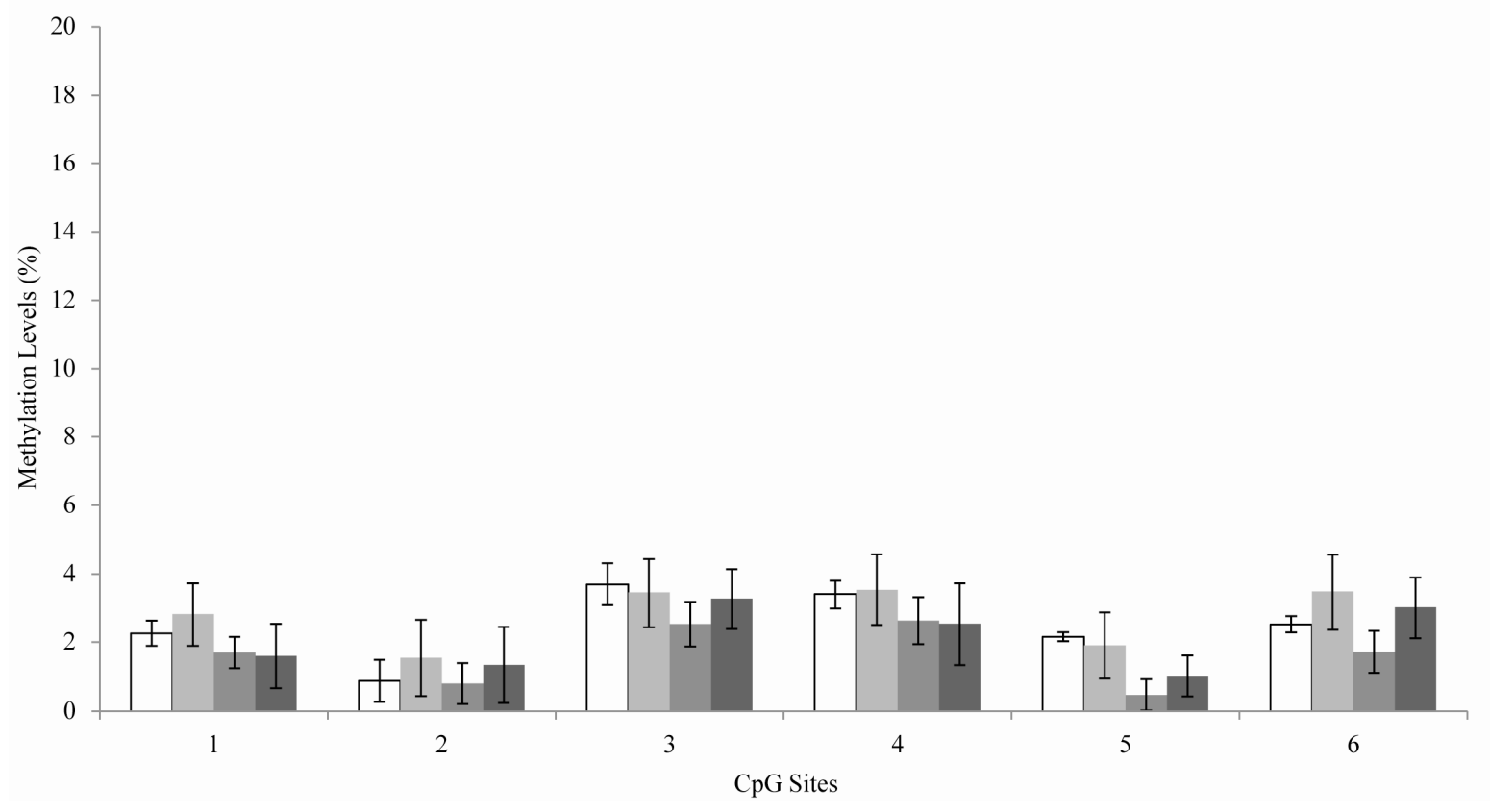

(a)

IL12A CpG Island Methylation

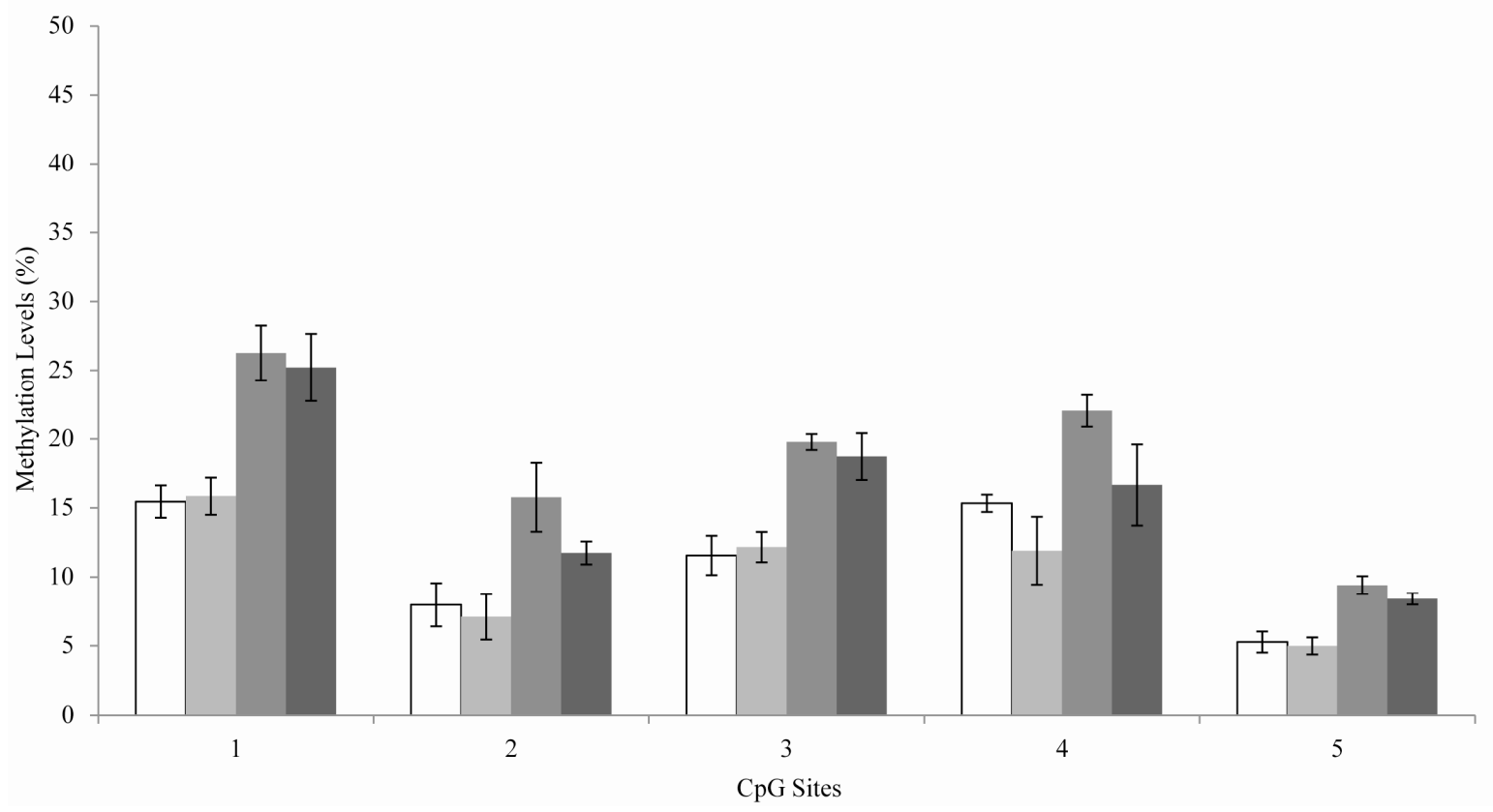

(b)

Figure 2. DNA methylation level at CpG islands (CGIs) upstreams of $S T A T 1$ (a) and $I L 12 A$ (b) were detected by pyrosequencing ( $\mathrm{n}=$ 4 , mean $\pm \mathrm{SD}$ ). $\mathrm{L} 7_{2}$.inf: infected line $7_{2} ; \mathrm{L}_{2}$.non: non-infected line $7_{2} ; \mathrm{L}_{3}$.non: non-infected line $6_{3} ; \mathrm{L} 6_{3}$.inf: infected line $6_{3}$.

Moreover, the methylation variations showed different trends in the $4 \mathrm{CpG}$ sites. In line $7_{2}$, the methylation levels in the first three CpG sites were significantly decreased after MDV infection ( $<<0.05$ or $\mathrm{p}<0.01$ ), and methylation level of the last CpG site was not significantly decreased $(p>0.05)$. In contrast, in line $6_{3}$, the methylation levels of the first two CpG sites were significantly declined by more than $10 \%$, which was similar to the changes in line $7_{2}$. At the third CpG site, the methylation level was dramatically increased after MDV infection ( $p<0.01)$, and the slightly increased methylation level was also observed at the fourth $\mathrm{CpG}$ site ( $\mathrm{p}>$ 


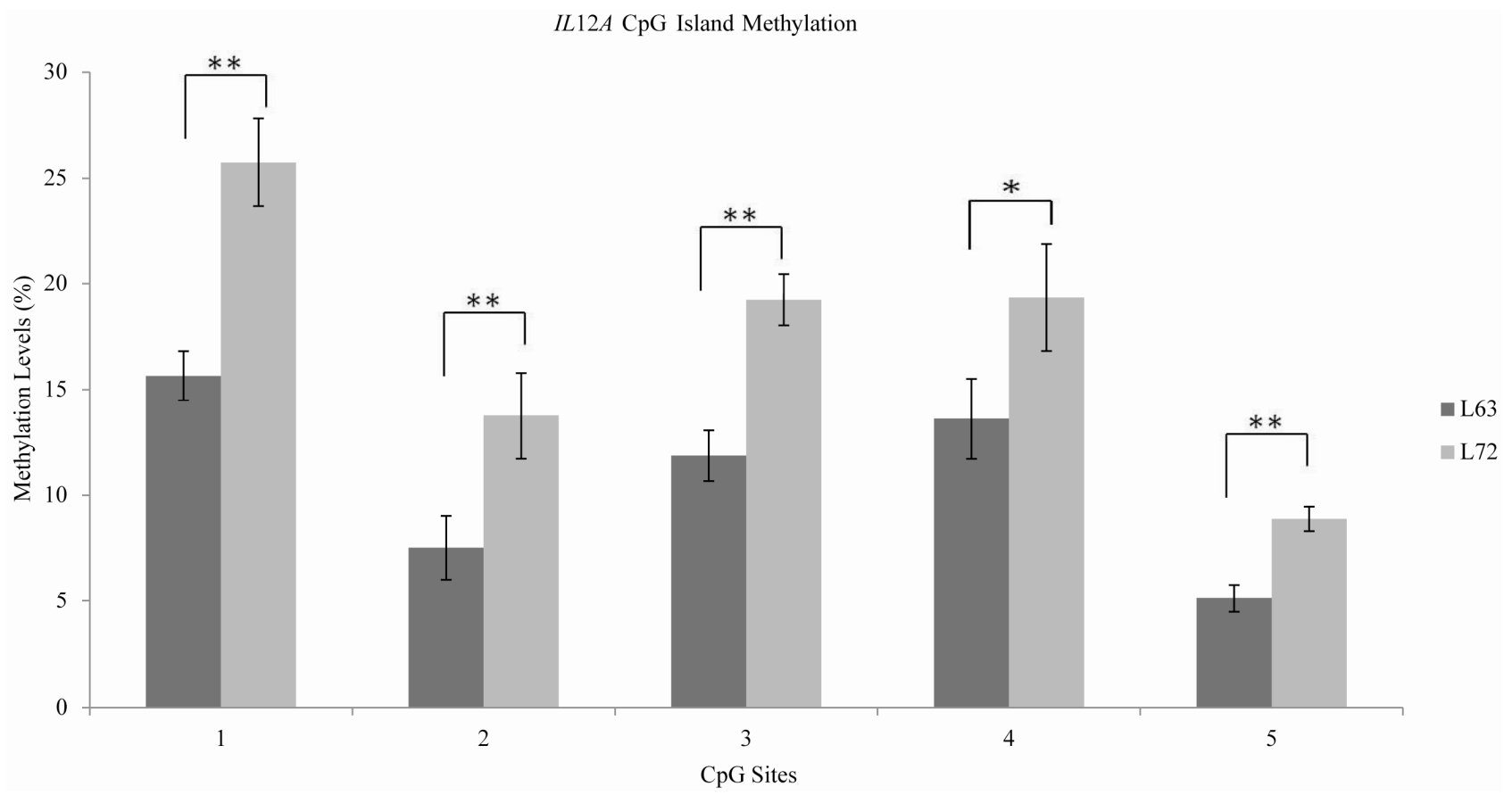

Figure 3. DNA methylation level at CpG islands (CGIs) upstream of $I L 12 A$ were detected by pyrosequencing ( $\mathrm{n}=8$ from each chicken line, including 4 control birds and $4 \mathrm{MDV}$ infected birds, mean $\pm \mathrm{SD}$ ). The one or two asterisks denote the methylation level at the CpG sites was significantly different with $\mathrm{p}<0.05$ or $\mathrm{p}<0.01$. $\mathrm{L7}_{2}$ : line $7_{2}$; $\mathrm{L6}_{3}$ : line $6_{3}$.

0.05).

As for the $I L 12 A \_C R 1 \_F$ element, it locates at 732 bp upstream of TSS. Four CpG sites were examined by bisulfite sequencing. As demonstrated in Figure 4(b), the methylation levels were enhanced in this region in infected chickens, from $36.7 \%$ to $56.7 \%$ in line $6_{3}$ and $50 \%$ to $75 \%$ line $7_{2}$, respectively. However, the increased average methylation in infected groups was largely due to the occurrence of hypermethylation at the second and third CpG sites in infected line $6_{3}$, and first and fourth CpG sites in infected line $7_{2}$. After further sequencing analysis, we found that $80 \%$ of the last CpG site in this element was mutated to AT in line $6_{3}$ birds regardless of infection (Figure 4(c)). The mutation at the CpG sites in line $6_{3}$ resulted in decreasing methylation level of the entire region in line $6_{3}$ compared to line $7_{2}$.

\subsection{Transcriptional Factor Binding Site Prediction}

To uncover the potential function of the CR1-F element methylation or mutation on gene expression, the transcriptional factor binding sites (TFBS) were predicted using sequences of CR1-F elements upstream of STAT1 and $I L 12 A$, respectively. By computational prediction, as shown in Table 2, we found that CR1-F upstream of STAT1 contained two GATA-1 recognition sites, at 360 370 bp and 578 - 593 bp regions. The fourth CpG site was resided in the second putative GATA-1 binding site
(Table 2). Comparatively, two putative binding sites were predicted in $I L 12 A$. E47 and $M Z F 1$ were located at the 16 - 20 bp and 117 - 124 bp of CR1-F upstream of $I L 12 A$, respectively. The putative $E 47$ binding site contains at the first CpG site of the CR1-F element. The mutation, 12 bp away from the predicted $M Z F 1$ binding site, did not change the TFBS prediction results (Table 2).

\section{DISCUSSION}

Latency is a crucial step to establish permanent immunosuppression in MDV infection [17]. It has been proven that the differences in viral load were detectable at $10 \mathrm{dpi}$ in the spleen of infected line $6_{3}$ and $7_{2}$ chickens [2]. Therefore, all the spleen samples were collected at $10 \mathrm{dpi}$ to elucidate the influence of MDV infection on host gene

Table 2. Transcription factor predicted in CR1-F elements.

\begin{tabular}{ccccl}
\hline $\begin{array}{c}\text { Transcription }_{\text {Factors }^{A}} \\
\text { GATA-1 }\end{array}$ & Gene $^{\mathbf{B}}$ & Position & Score $^{\mathrm{C}}$ & \multicolumn{1}{c}{ Core Sequence $^{\mathbf{D}}$} \\
SATA 1 & $S T A T-370$ & 93.1 & GCTGATAGGA \\
$E 47$ & IL12A & $16-29$ & 90.4 & ACAGCTGCCCGGGG \\
$M Z F 1$ & $I L 12 A$ & $117-124$ & 91.3 & GTTGGGGA \\
\hline
\end{tabular}

${ }^{A}$ : Names of transcription factors; ${ }^{\mathrm{B}}$ : Genes located downstream of the CR1-F elements; ${ }^{\text {C: }}$ Calculated based on matrix similarity; ${ }^{\mathrm{D}}$ : Sequences of predicted TFBS. 
expression and DNA methylation. In our previous study, we proved the MDV was successfully challenged in both line $6_{3}$ and $7_{2}$, and replicated faster in infected line $7_{2}$ than line $6_{3}[16]$.

STAT1, a member of STAT protein family, acts as a transcriptional activator and mediates gene expression in response to pathogens [21]. STAT1 transcription was induced by MDV challenge in the early cytolytic phase at 5 dpi [17]. Here, we found that its expression was also significantly activated at latency in infected line $7_{2}(\mathrm{p}<$ $0.05)$, but not in infected line $6_{3}(\mathrm{p}<0.05)$. It was reported that $I L 12 A$ interacts with $I L 12 B$ to form a cytokine $I L 12$, and stimulates downstream signaling pathways for innate immunity [22]. After MDV infection,
IL12A was upregulated in the lytic infection (5 dpi) [23]. In our study, we found the IL12A mRNA level was continuously elevated at latent stage, further illustrating the importance of $I L 12 A$ in MD pathogenesis.

DNA methylation fluctuation triggered by virus infection has been well documented [24,25]. Recently, distinct DNA methylation patterns were identified in MD susceptible chickens after exposure to MDV [6]. In this study, we found that promoter CGI methylation remains either very low or stable after MDV challenge, whereas the methylation status of two CR1-F elements, further upstream of promoter CGIs, was altered upon MDV challenge, agreeing with previous research [26]. It has been found that true differential methylation regions were not

STAT1 CR1-F Methylation

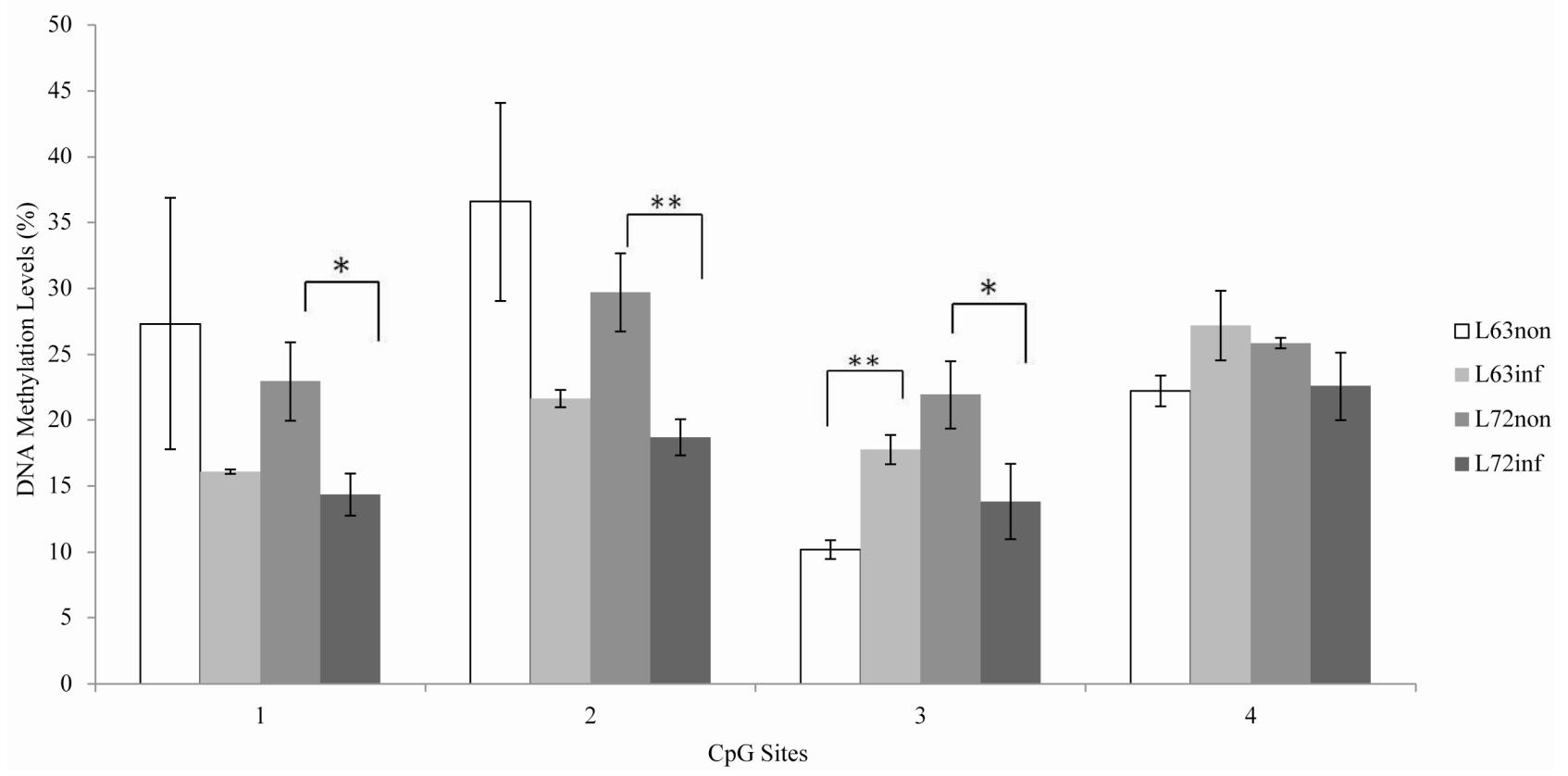

(a)

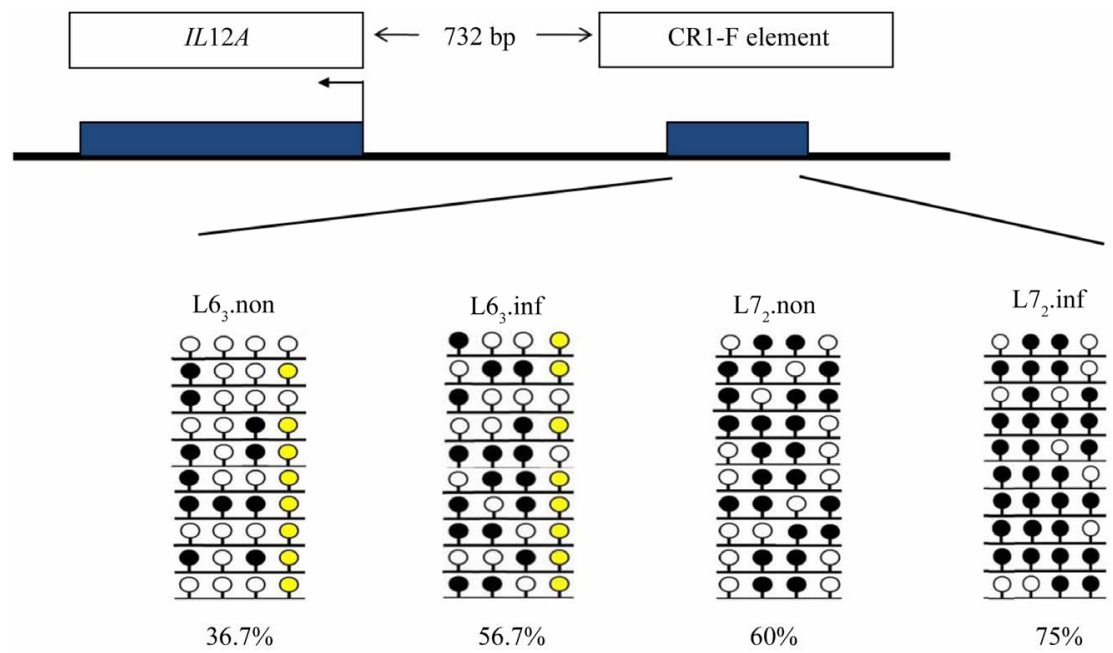

(b) 


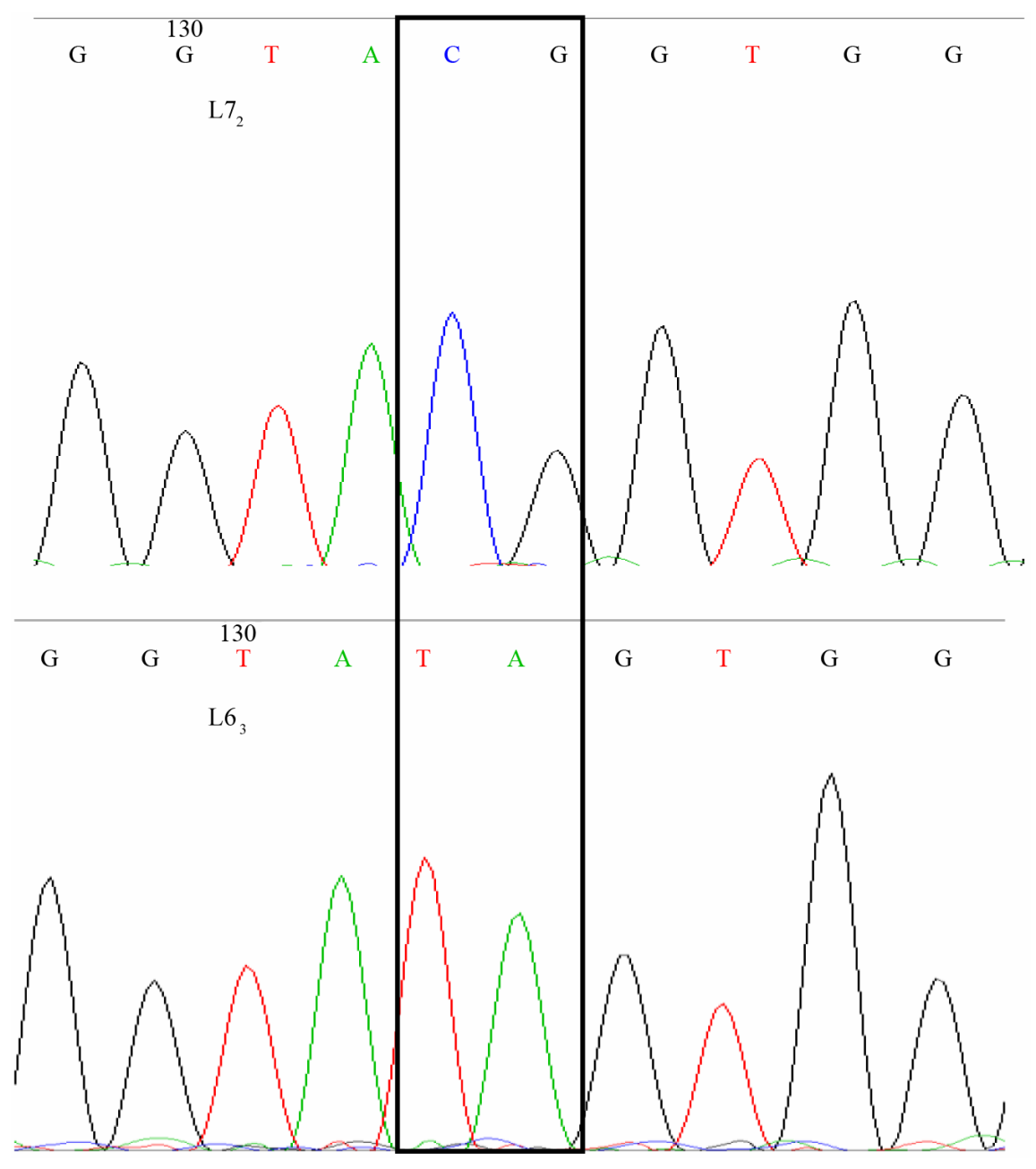

(c)

Figure 4. (a) DNA methylation level at CR1-F upstream of STAT1 was measured by pyrosequencing $(n=4$, mean \pm SD). The one or two asterisks indicate the methylation level was significantly different with $\mathrm{p}<0.05$ or $\mathrm{p}<0.01$. L $7_{2}$.inf: infected line $7_{2}$; L $7_{2} \cdot$ non: non-infected line $7_{2}$; L6 3 .non: non-infected line $6_{3}$; L6 3 .inf: infected line $66_{3}$; (b) DNA methylation level at CR1-F upstream of IL12A was measured by bisulfite sequencing. From each group, 10 clones were sequenced. The top panel indicates the position of $I L 12 A$ gene and CR1-F elements, and the arrow denotes the direction of transcription start sites. In bottom panel, the open circle denotes ummethylated $\mathrm{CpG}$, the black circle denotes the methylated $\mathrm{CpG}$, and yellow circle denotes the mutation. $\mathrm{L} 7_{2}$.inf: infected line $7_{2}$; L7 7 .non: non-infected line $7_{2}$; L6 6 .non: non-infected line $6_{3}$; L6 $6_{3}$.inf: infected line $6_{3}$; (c) The mutations in $I L 12 A \_C R 1$ F were identified in line $6_{3}$, pointed out by the square, and the top is the sequences in line $7_{2}$, and bottom is sequence from line $6_{3}$. $L 7_{2}$ : line $7_{2}$; L6 $6_{3}$ : line $6_{3}$.

in the $\mathrm{CpG}$ island but in the low $\mathrm{CpG}$ density regions near the traditional CpG islands [26]. These results suggest that, instead of the CGIs at promoter regions, the methylation level of CR1-F elements might be influenced by MDV infection.

As we have known, about $25 \%$ of human gene promoter regions harbor sequences derived from TEs, indicating the potential contribution of TEs to regulatory elements [27]. Interestingly, the CR1 also contains putative TFBSs. Two GATA-1 binding sites were predicted in the CR1-F element upstream of STAT1, and their sequences were same as the chicken GATA binding consensus sequence WGATAR, in which $\mathrm{W}$ and $\mathrm{R}$ refer to
A/T and A/G, respectively [28]. The regulation of GATA-1 on STAT1 transcription has been proven in mice [29], we thus speculated that GATA-1 might control chicken STAT1 expression with the same manner. Moreover, DNA methylation regulates gene expression by blocking transcription factor binding [30,31]. Therefore, we hypothesized that DNA demethylation induced by MDV infection in CR1-F might mediate the GATA-1 binding to the upstream of $S T A T 1$ and thereby enhance its expression. The methylation level of the last two CpG sites, where the putative GATA-1 binding site is located, was enhanced in line $6_{3}$ after MDV infection, but declined in line $7_{2}$. This difference may help us explain the smaller 
upregulation of $S T A T 1$ transcription in line $6_{3}$ than in line 72 . The hypothesis will be confirmed in the future.

In contrast, MDV infection was associated with not only the increased methylation level of CR1-F element near $I L 12 A$, but also increased $I L 12 A$ mRNA levels. We reasoned that the increased methylation level may reduce the binding affinity of myeloid zinc finger protein 1 $(M Z F 1)$ and E47, two transcriptional repressors [32,33], hereby explaining the correlation of increased methylation levels at $I L 12 A \_C R 1-F$ element and the activation of $I L 12 A$ transcription after MDV infection in line $6_{3}$ and line $7_{2}$. We also observed that $I L 12 A$ was also more actively transcribed in line $6_{3}$ than line $7_{2}$ regardless of MDV infection. In control groups, IL12A mRNA was about $30 \%$ higher in line $6_{3}$ than in line $7_{2}$ although not statistically significant ( $p=0.2$ ); in infected groups, line $6_{3}$ had significantly higher $I L 12 A$ mRNA level than line 72 . Correspondingly, the promoter CGI and IL12A_CR1-F element were greatly methylated in line $7_{2}$ compared to line $6_{3}$ despite MDV infection (Figures 3 and 4(b)), implicating that the repression of $I L 12 A$ transcription was probably mediated by the methylation at both the promoter and CR1-F region. Therefore, the methylation at promoter CGI and upstream CR1-F elements may contribute to transcriptional differences in $I L 12 A$ in line $6_{3}$ and line $7_{2}$. Because the methylation on promoter region was stable, we think the MDV infection triggered the methylation alterations at $I L 12 A$ CR1-F element, which may be involved in the transcription stimulation of $I L 12 A$ in MDV infection. Moreover, it has been reported that the increased number of methylated CpG sites at the distal region inhibited the activity of adjacent gene promoter [34]. Therefore, we assume that the mutation at CR1 region in line $6_{3}$ may affect the activity of $I L 12 A$ in line $6_{3}$. Taken together, the methylation change on $I L 12 A \_$CR1-F element was most likely involved in the transcription stimulation of $I L 12 A$ in response to MDV infection in two lines. The differences in genetic and epigenetic aspects, in terms of SNPs and DNA methylation patterns, may comprehensively account for the difference of $I L 12 A$ mRNA levels between two lines.

Collectively, MDV challenge activated STAT1 and $I L 12 A$ transcription in the MD resistant line $6_{3}$ and susceptible line $7_{2}$ chickens at the latency. The methylation status at the promoter CpG islands of STAT1 and IL12A were stable after MDV infection. The enhanced expression levels of the two immune-related genes might be mediated by DNA methylation variations at the upstream CR1-F elements, the chicken repetitive DNA sequences. These results indicated that these two CR1-F elements were presumably cis-regulatory sequences and their methylation alterations thereby might be involved in responses to MDV infection. Further work is required to demonstrate the biological functions of the CR1-F ele- ments and the influences of DNA methylation on transcription factor binding affinity and gene expression.

\section{ACKNOWLEDGEMENTS}

This project was supported by National Research Initiative Competitive Grant no. 2008-35204-04660 and no. 2010-65205-20588 from the USDA National Institute of Food and Agriculture. The comments from two anonymous reviewers greatly improved the quality of the manuscript.

\section{REFERENCES}

[1] Davison, T.F. and Nair, V. (2004) Marek’s disease: An evolving problem. Elsevier, Boston.

[2] Kaiser, P., Underwood, G. and Davison, F. (2003) Differential cytokine responses following Marek's disease virus infection of chickens differing in resistance to Marek's disease. Journal of Virology, 77, 762-768. doi:10.1128/JVI.77.1.762-768.2003

[3] Abdul-Careem, M.F., Hunter, B.D., Sarson, A.J., Mayameei, A., Zhou, H. and Sharif, S. (2006) Marek's disease virus-induced transient paralysis is associated with cytokine gene expression in the nervous system. Viral Immunolog, 19, 167-176. doi:10.1089/vim.2006.19.167

[4] Sarson, A.J., Parvizi, P., Lepp, D., Quinton, M. and Sharif, S. (2008) Transcriptional analysis of host responses to Marek's disease virus infection in genetically resistant and susceptible chickens. Animal Genetics, 39, 232-240. doi:10.1111/j.1365-2052.2008.01710.x

[5] Baylin, S.B. and Ohm, J.E. (2006) Epigenetic gene silencing in cancer: A mechanism for early oncogenic pathway addiction? Nature Reviews Cancer, 6, 107-116. doi:10.1038/nrc1799

[6] Luo, J., Yu, Y., Zhang, H., Tian, F., Chang, S., Cheng, H.H. and Song, J. (2011) Down-regulation of promoter methylation level of CD4 gene after MDV infection in MD-susceptible chicken line. BMC Proceedings, 5, S7. doi:10.1186/1753-6561-5-S4-S7

[7] Osterrieder, N., Kamil, J.P., Schumacher, D., Tischer, B.K. and Trapp, S. (2006) Marek's disease virus: From miasma to model. Nature Reviews Microbioloy, 4, 283294. doi:10.1038/nrmicro1382

[8] Burch, J.B., Davis, D.L. and Haas, N.B. (1993) Chicken repeat 1 elements contain a pol-like open reading frame and belong to the non-long terminal repeat class of retrotransposons. Proceedings of National Academy of Science USA, 90, 8199-8203. doi:10.1073/pnas.90.17.8199

[9] Vandergon, T.L. and Reitman, M. (1994) Evolution of chicken repeat 1 (CR1) elements: Evidence for ancient subfamilies and multiple progenitors. Molecular Biology and Evolution, 11, 886-898.

[10] Hiller, L.W. (2004) Sequence and comparative analysis of the chicken genome provide unique perspectives on vertebrate evolution. Nature, 432, 695-716. doi:10.1038/nature03154

[11] Wallis, J.W., Aerts, J., Groenen, M.A., Crooijmans, R.P., 
Layman, D., Graves, T.A., Scheer, D.E., Kremitzki, C., Fedele, M.J., Mudd, N.K. et al. (2004) A physical map of the chicken genome. Nature, 432, 761-764. doi:10.1038/nature03030

[12] Wong, G.K., Liu, B., Wang, J., Zhang, Y., Yang, X., Zhang, Z., Meng, Q., Zhou, J., Li, D., Zhang, J., et al. (2004) A genetic variation map for chicken with 2.8 million single-nucleotide polymorphisms. Nature, 432, 717722. doi:10.1038/nature03156

[13] Feinberg, A.P., Tycko, B. (2004) The history of cancer epigenetics. Nature Reviews Cancer, 4, 143-153. doi:10.1038/nrc1279

[14] Suter, C.M., Martin, D.I. and Ward, R.L. (2004) Hypomethylation of $\mathrm{L} 1$ retrotransposons in colorectal cancer and adjacent normal tissue. International Journal Colorectal Diseaase, 19, 95-101. doi:10.1007/s00384-003-0539-3

[15] Bacon, L.D., Hunt, H.D. and Cheng, H.H. (2000) A review of the development of chicken lines to resolve genes determining resistance to diseases. Poultry Science, 79, 1082-1093.

[16] Tian, F., Luo, J., Zhang, H., Chang, S. and Song, J. (2012) MiRNA expression signatures induced by Marek's disease virus infection in chickens. Genomics, 99,152-159. doi:10.1016/j.ygeno.2011.11.004

[17] Heidari, M., Sarson, A.J., Huebner, M., Sharif, S., Kireev, D. and Zhou, H. (2010) Marek's disease virus-induced immunosuppression: Array analysis of chicken immune response gene expression profiling. Viral Immunology, 23, 309-319. doi:10.1089/vim.2009.0079

[18] Parvizi, P., Read, L.R., Abdul-Careem, M.F., Sarson, A.J., Lusty, C., Lambourne, M., Thanthrige-Don, N., Burgess, S.C. and Sharif, S. (2009) Cytokine gene expression in splenic $\mathrm{CD}^{+}$and $\mathrm{CD8}^{+} \mathrm{T}$ cell subsets of genetically resistant and susceptible chickens infected with Marek's disease virus. Veterniary Immunology and Immunopathology, 132, 209-217. doi:10.1016/j.vetimm.2009.06.009

[19] Parvizi, P., Read, L., Abdul-Careem, M.F., Lusty, C. and Sharif, S. (2009) Cytokine gene expression in splenic $\mathrm{CD}^{+}$and $\mathrm{CD}^{+} \mathrm{T}$-cell subsets of chickens infected with Marek’s disease virus. Viral Immunology, 22, 31-38. doi:10.1089/vim.2008.0062

[20] Heinemeyer, T., Wingender, E., Reuter, I., Hermjakob, H., Kel, A.E., Kel, O.V., Ignatieva, E.V., Ananko, E.A., Podkolodnaya, O.A., Kolpakov, F.A., et al. (1998) Databases on transcriptional regulation: TRANSFAC, TRRD and COMPEL. Nucleic Acids Research, 26, 362-367. doi:10.1093/nar/26.1.362

[21] Katze, M.G., et al. (2002) Viruses and interferon: A fight for supremacy. Nature Reviews Immunology, 2, 675-687. doi:10.1038/nri888

[22] Kalinski, P., Hilkens, C.M., Snijders, A., Snijdewint, F.G. and Kapsenberg, M.L. (1997) IL-12-deficient dendritic cells, generated in the presence of prostaglandin E2, promote type 2 cytokine production in maturing human naive T helper cells. Journal of Immunology, 159, 28-35.

[23] Heidari, M., Zhang, H.M. and Sharif, S. (2008) Marek’s disease virus induces Th-2 activity during cytolytic infec- tion. Viral Immunology, 21, 203-214. doi:10.1089/vim.2007.0078

[24] Su, P.F., Lee, T.C., Lin, P.J., Lee, P.H., Jeng, Y.M., Chen, C.H., Liang, J.D., Chiou, L.L., Huang, G.T. and Lee, H.S. (2007) Differential DNA methylation associated with hepatitis B virus infection in hepatocellular carcinoma. Intertnational Journal of Cancer, 121, 1257-1264. doi:10.1002/ijc.22849

[25] Tong, J.H., Tsang, R.K., Lo, K.W., Woo, J.K., Kwong, J., Chan, M.W., Chang, A.R., van Hasselt, C.A., Huang, D.P. and To, K.F. (2002) Quantitative Epstein-Barr virus DNA analysis and detection of gene promoter hypermethylation in nasopharyngeal (NP) brushing samples from patients with NP carcinoma. Clinic Cancer Research, 8, 2612-2619.

[26] Doi, A., Park, I.H., Wen, B., Murakami, P., Aryee, M.J., Irizarry, R., Herb, B., Ladd-Acosta, C., Rho, J., Loewer, S., et al. (2009) Differential methylation of tissue- and cancer-specific CpG island shores distinguishes human induced pluripotent stem cells, embryonic stem cells and fibroblasts. Nature Genetics, 41, 1350-1353. doi:10.1038/ng.471

[27] Jordan, I.K., Rogozin, I.B., Glazko, G.V. and Koonin, E.V. (2003) Origin of a substantial fraction of human regulatory sequences from transposable elements. Trends in Genetics, 19, 68-72. doi:10.1016/S0168-9525(02)00006-9

[28] Merika, M. and Orkin S.H. (1993) DNA-binding specificity of GATA family transcription factors. Molecular and Cellular Biology, 13, 3999-4010.

[29] Huang, Z., Richmond, T.D., Muntean, A.G., Barber, D.L., Weiss, M.J. and Crispino, J.D. (2007) STAT1 promotes megakaryopoiesis downstream of GATA-1 in mice. Journal of Clinical Investigation, 117, 3890-3899. doi:10.1172/JCI33010

[30] Deng, G., Chen, A., Pong, E. and Kim, Y.S. (2001) Methylation in hMLH1 promoter interferes with its binding to transcription factor CBF and inhibits gene expression. Oncogene, 20, 7120-7127. doi:10.1038/sj.onc.1204891

[31] Lucas, M.E., Crider, K.S., Powell, D.R., Kapoor-Vazirani, P. and Vertino, P.M. (2009) Methylation-sensitive regulation of TMS1/ASC by the ETS factor, GA-binding protein-alpha. Journal of Biological Chemistry, 284, 1469814709. doi:10.1074/jbc.M901104200

[32] Yan, Q.W., Reed, E., Zhong, X.S., Thornton, K., Guo, Y. and Yu, J.J. (2006) MZF1 possesses a repressively regulatory function in ERCC1 expression. Biochemical Pharmacoogy, 71, 761-771.

[33] Yang, Y., Contag, C.H., Felsher, D., Shachaf, C.M., Cao, Y., Herzenberg, L.A., Herzenberg, L.A. and Tung, J.W. (2004) The E47 transcription factor negatively regulates CD5 expression during thymocyte development. Proceedings of National Academy of Science USA, 101, 3898-3902. doi:10.1073/pnas.0308764101

[34] Curradi, M., Izzo, A., Badaracco, G. and Landsberger, N. (2002) Molecular mechanisms of gene silencing mediated by DNA methylation. Molecular and Cellular Biology, 22, 3157-3173. doi:10.1128/MCB.22.9.3157-3173.2002 